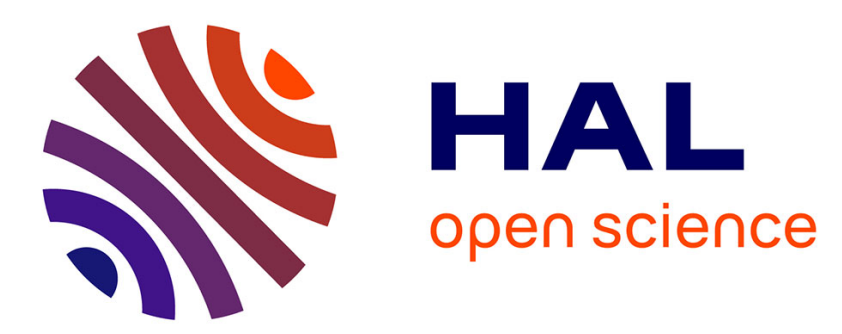

\title{
High resolution Bragg-Fresnel optics for nanometer scale methods with soft X-rays
}

\author{
A. Erko
}

\section{To cite this version:}

A. Erko. High resolution Bragg-Fresnel optics for nanometer scale methods with soft X-rays. Journal de Physique IV Proceedings, 1994, 04 (C9), pp.C9-245-C9-251. 10.1051/jp4:1994943 . jpa-00253504

\section{HAL Id: jpa-00253504 https://hal.science/jpa-00253504}

Submitted on 1 Jan 1994

HAL is a multi-disciplinary open access archive for the deposit and dissemination of scientific research documents, whether they are published or not. The documents may come from teaching and research institutions in France or abroad, or from public or private research centers.
L'archive ouverte pluridisciplinaire HAL, est destinée au dépôt et à la diffusion de documents scientifiques de niveau recherche, publiés ou non, émanant des établissements d'enseignement et de recherche français ou étrangers, des laboratoires publics ou privés. 


\title{
High resolution Bragg-Fresnel optics for nanometer scale methods with soft X-rays
}

\author{
A. Erko
}

Institute of Microelectronics Technology, Russian Academy of Sciences, Laboratory of X-Ray Optics and Technology, 142432 Chernogolovka, Russia

\begin{abstract}
The main principles and some applications of Bragg-Fresnel multilayer optics are described. An elliptical Bragg-Fresnel multilayer lens (BFML), designed and fabricated in the IMT RAS has been used for 2-dimensional focusing of the white X-ray synchrotron beam. For the beam energy of about $12 \mathrm{KeV}$ the spot size checked with the knife edge method was about $1 \mu \mathrm{m}$. As an example of a successful application of this optical element in $\mathrm{x}$-ray imaging, the fluorescence X-Ray scanning LURE-IMT microprobe is discussed. The results of 2-D scanning images with submicron resolution of a test object in transmission and fluorescence mode are also presented.
\end{abstract}

\section{INTRODUCTION}

The use of nanometer radiation as a tool for microscopy and nanometer technology is developing very rapidly. This can be attributed to the development of synchrotron radiation sources and on the progress in the development of optical elements and methods for the Xrays beams control such as focusing and modulation. The future of this technique is also very promising with the advent of $\mathrm{X}$-ray lasers.

The present day stage of developing new optics for $\mathrm{x}$-ray beams calls for creating effective focusing elements with the structure of three dimensional Fresnel zones : Bragg-Fresnel optics. Multilayer mirrors and crystals are the basis for such elements. These structures are the first elements of microphotonics as they allow for transforming the information of electrical, optical or acoustic signals into $\mathrm{X}$-ray beam modulation.

In 1963, Yu.N. Denisiuk published an idea to use a combination of volume Bragg diffraction and Fresnel or Fraunhofer diffraction for recording and reconstruction of optical holographic images [1]. The first proposal for the application of this technique to X-ray focusing was done by V.V.Aristov [2]. In this new kind of X-ray optical system, a crystal or a multilayer acts as the Bragg reflector. Experiments were done using both kinds, ion etched crystals [3] and multilayers [4,5]. In principle a Bragg-Fresnel multilayer lens (BFML) keeps the advantage of the Fresnel zone plates, which offer a high spatial resolution when used in transmission. The use of multilayer static and dynamical gratings is also very promising [6,7].

\section{BFML DESIGN}

A perfect BFML is a 3D system of isophase surfaces reflecting an interference pattern of a divergent spherical wave from a point $A_{\lambda}$ (source) to a convergent spherical wave in point $A_{2}$ (image) [8]. For a wavelength $\lambda$, reflected to point $A_{2}$, the distance between the successive surfaces is such that a path difference is a multiple of $\lambda$.

To obtain 2D focusing with a flat Bragg reflector, one needs to produce a volume structure as indicated schematically in fig.1. In fact, due to the limited penetration depth of the X-rays, the multilayer structures we used can have a rectangular profile. Fig.1 shows the formation of 3-dimensional Fresnel zones. In our experiment we used multilayer W/Si and W/C mirrors prepared by magnetron sputtering on a thick super polished silicon wafer. The period spacing of the bilayers was in the range about $2.5 \mathrm{~nm}-3.5 \mathrm{~nm}$. A number of bilayers of the order of 
order of 60-100 were prepared, and an experimental multilayer reflectivity of $60 \%-75 \%$ at $0.154 \mathrm{~nm}$ was measured.

To provide two-dimensional point focusing the special designing and fabrication of elliptical BFML were done.

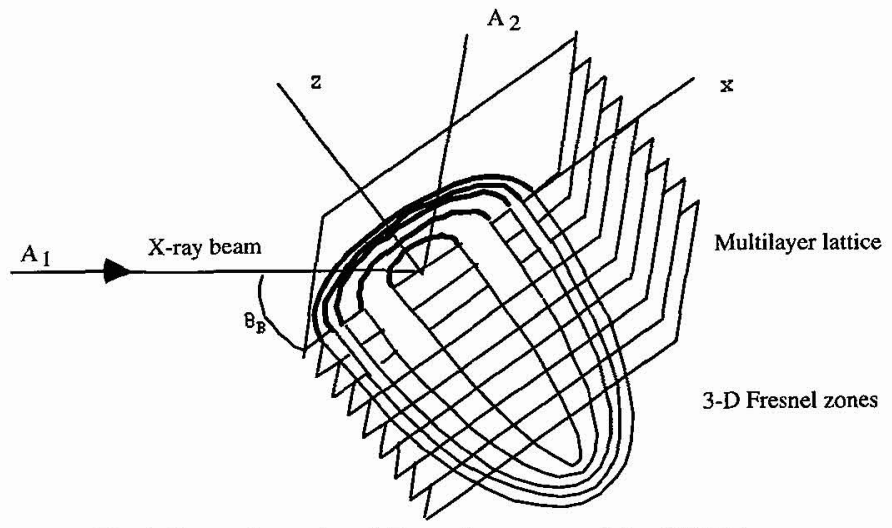

Fig. I Three-dimensional Fresnel structure of the BFML lens.

Electron beam and optical lithography, ion-beam etching processes are successively employed to obtain a BFML. In our laboratory a ZRM-12 electron-beam instrument with the modified computer control system has been applied for the generation of an elliptical-shaped topology of a BFML. The hardware as well as software for the IMT RAS exposure system was developed to provide topology fabrication of complex optical elements. Linear spline approximation of the analytical diffraction lenses formulas was used for exposure data preparation. Recently a new software has been developed to provide correction of the scan field distortion as well and can be used for the fabrication of optical elements in large fields [9]. Special attention to the structure fabrication accuracy has been paid. Software for exposure data acquisition includes the experimental parameters of exposure field distortion. The RFexcited argon ion-beam source for the BFML structure etching in multilayer depth was used.
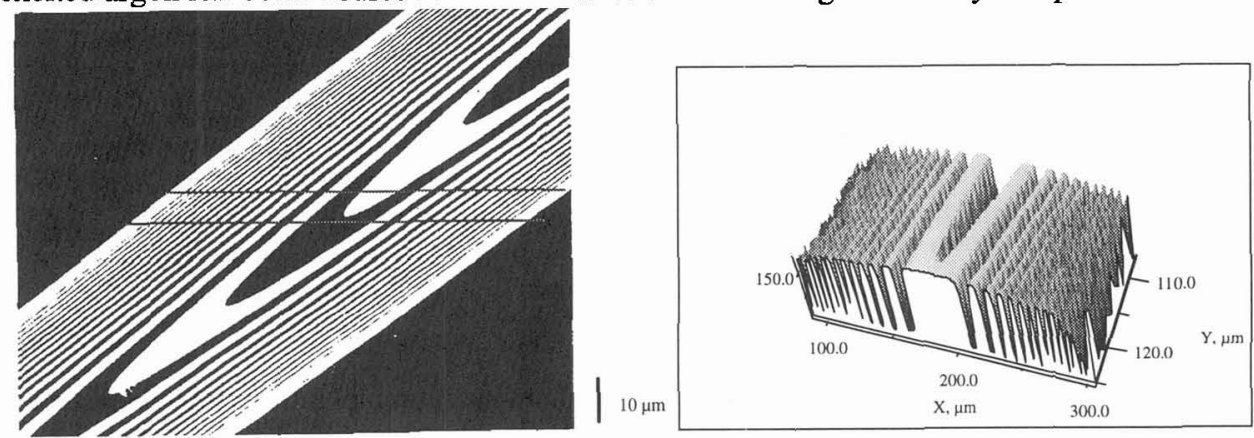

Fig.2 Microphotograph of the elliptical BFML, general view (a) and BFML cross-section (b).

To avoid a scattering from the mirror around BFML the second lithography-etching procedure was performed through a special aperture mask. The aperture mask was patterned in a layer of $\mathrm{Fe}_{2} \mathrm{O}_{3}$ on a glass substrate by electron beam lithography and wet etching. Then we 
used this mask for UV lithography on the multilayer coated with photoresist. Finally, we etched the multilayer down to the substrate through the photoresist mask by using the same RF-excited ion-beam source.

The typical BFML, designed for $12.4 \mathrm{KeV}$ radiation is shown in fig.2. This lens was prepared on a 60 bilayer $3.2 \mathrm{~nm}$ period W/C multilayer mirror coated by magnetron sputtering (prepared by A.Yakshin, IMT RAS). An ALCATEL SCM-651 coating system, designed with the help of B. Vidal (LOE, Marseille, France) was used for the multilayer preparation. The characteristics of the lens are given in the Table 1.

Table 1

\begin{tabular}{c|c|c|c|c|c|}
\hline Lens & $\begin{array}{c}\text { Wavelength } \\
\text { (Energy) }\end{array}$ & Dimensions & $\begin{array}{c}\text { Multilayer } \\
\text { period }\end{array}$ & $\begin{array}{c}\text { Minimum zone } \\
\text { width }\end{array}$ & $\begin{array}{c}\text { Focal } \\
\text { length }\end{array}$ \\
\hline $\mathrm{n}^{\circ} 1$ & $\begin{array}{c}0.1 \mathrm{~nm} \\
(12.4 \mathrm{KeV})\end{array}$ & $\begin{array}{c}59 \mu \mathrm{m} \\
\mathrm{X}\end{array}$ & $3.25 \mathrm{~nm}$ & $250 \mathrm{~nm}$ & $15 \mathrm{~cm}$ \\
& & $2.48 \mathrm{~mm}$ & $10.7 \mu \mathrm{m}$ & 15 \\
\hline
\end{tabular}

\section{BFML RESOLUTION AND EFFICIENCY}

The main limitations of BFML resolution are due to technological parameters and aberrations. Existing technology limits a minimum zone size to about $0.1 \mu \mathrm{m}$. Aberrations are more serious especially at a small angle of incidence.

To analyze the off-axis aberrations, one can use an optical path difference assuming a rectangular groove profile. Using the optical path representation it is possible to find the analytical expression for main off-axis aberrations: coma, astigmatism and field curvature. According to the Rayleigh criterion, angle of view, limited by coma, astigmatism and field curvature is equal to:

$$
\begin{aligned}
& \alpha_{\mathrm{coma}}=\frac{\Delta \mathrm{r}_{\min }^{2}}{\lambda \mathrm{F}}\left[\frac{\lambda}{4 \Delta \mathrm{r}_{\min }\left(1+\frac{\lambda}{2 \Delta \mathrm{r}_{\min }} \cot \theta_{\mathrm{B}}\right)^{3}}+\frac{\cot \theta_{\mathrm{B}}}{1+\frac{\lambda}{2 \Delta \mathrm{r}_{\min }} \cot \theta_{\mathrm{B}}}\right]^{-1} \\
& \alpha_{\text {ast,f.cur }}=\sqrt{\frac{\Delta r_{\min }}{F}\left[\frac{3 \lambda}{4 \Delta r_{\text {min }}\left(1+\frac{\lambda}{2 \Delta r_{\text {min }}} \cot \theta_{B}\right)^{3}}+\frac{\cot \theta_{B}}{1+\frac{\lambda}{2 \Delta r_{\text {min }}} \cot \theta_{B}}\right]^{-1}}
\end{aligned}
$$

where $\Delta \mathrm{r}_{\text {mir }}$ is the minimum zone size;

$F$ is the focal length;

$\theta_{B}$ is the Bragg angle.

As an example, the field of view of the BFML lens characterized in the Table 1 is shown in the fig.3. This lens when used at the angle of incidence of $0.955^{\circ}$ has angle of view of about 12 $\mu \mathrm{rad}$ in one direction. Those parameters were chosen to demonstrate the importance of coma aberration at small angles and field curvature domination close to normal incidence.

Photographic resolution tests were performed for the fixed beam energy of $12.4 \mathrm{KeV}$ at the experimental set-up installed on the DCI storage ring (LURE, Orsay (France)). High resolution $(0.1 \mu \mathrm{m})$ VRE type photographic plates made in Russia have been used to test the spot configuration. Fig.4a shows the corresponding 3-D plot of the $50 \mu \mathrm{m} 42$ times reduced pinhole image. The best value of the observed focus spot was about $1.3 \mu \mathrm{m}$ in diameter. 


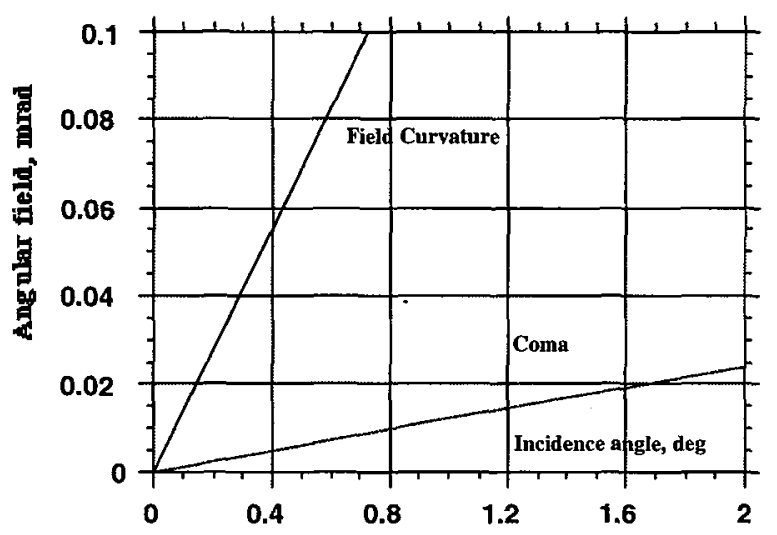

Fig. 3 Angular field of view of an elliptical BFML in plane of diffraction. Minimum zone width $0.25 \mu m$.

The optimal depth of the lens profile has been calculated according to the following ideas. The most zones, occupying the large area of the zone plate, have a lateral period larger than the extinction length, Lext, of the multilayer mirror, equal to $\sim 10 \mu \mathrm{m}$ for the particular multilayer and the Bragg conditions. Lext is equal to the extinction depth divided by the $\sin \theta_{\mathbf{R}}$. In this case the beam reflects mainly inside of the one period of the grating and an ordinary diffraction on the thin grating takes place producing a several diffraction orders inside the Bragg peak simultaneously. One can estimate the optimal profile depth corresponding to the maximum of the first order diffraction efficiency [7]. In the case of an amplitude-phase lens the efficiency can be evaluated by a simple formula proposed by Kirz [10]:

$$
\frac{\mathrm{I}_{1}}{\mathrm{I}_{0}}=\frac{\mathrm{R}[1+\exp (-\chi \pi)]^{2}}{\pi^{2}}
$$

where $\chi$ value is:

$$
\chi=\frac{\beta_{w} T_{w}+\beta_{C} T_{C}}{\delta_{w} T_{w}+\delta_{c} T_{C}}
$$

Our multilayer mirror, having a reflectivity $R=0.7$, would lead to a first order efficiency of roughly 0.25 , if our BFML was similar to a classical amplitude-phase grating. Experimental efficiencies in normalized units: the ratio of the focused energy to the total energy reflected into a $20 \mu \mathrm{m}$ output aperture of the BFML were found to be $16 \%$ at $12.4 \mathrm{KeV}$ and $10 \%$ at 8.3 $\mathrm{KeV}$. This value is in agreement with the theoretical prediction mentioned above for a classical amplitude-phase grating. This indicates the phase character of the obtained diffraction.

The number of photons experimentally obtained in the focal spot in the LURE test was on the order of $5 \times 10^{4}$ phot/sec [11]. Much better flux was obtained in the experiment at the European Synchrotron Radiation Facility (ESRF) [12]. In fig.4b is shown the 400 times reduced image of the undulator source at the ESRF "Troika" beam line. This experiment confirms a high radiation stability of BFML. Photon flux on the order of $10^{10} \mathrm{phot} / \mathrm{sec}$ in a focal spot of $2.5 \mu \mathrm{m} \times 5 \mu \mathrm{m}$ in size was obtained. 


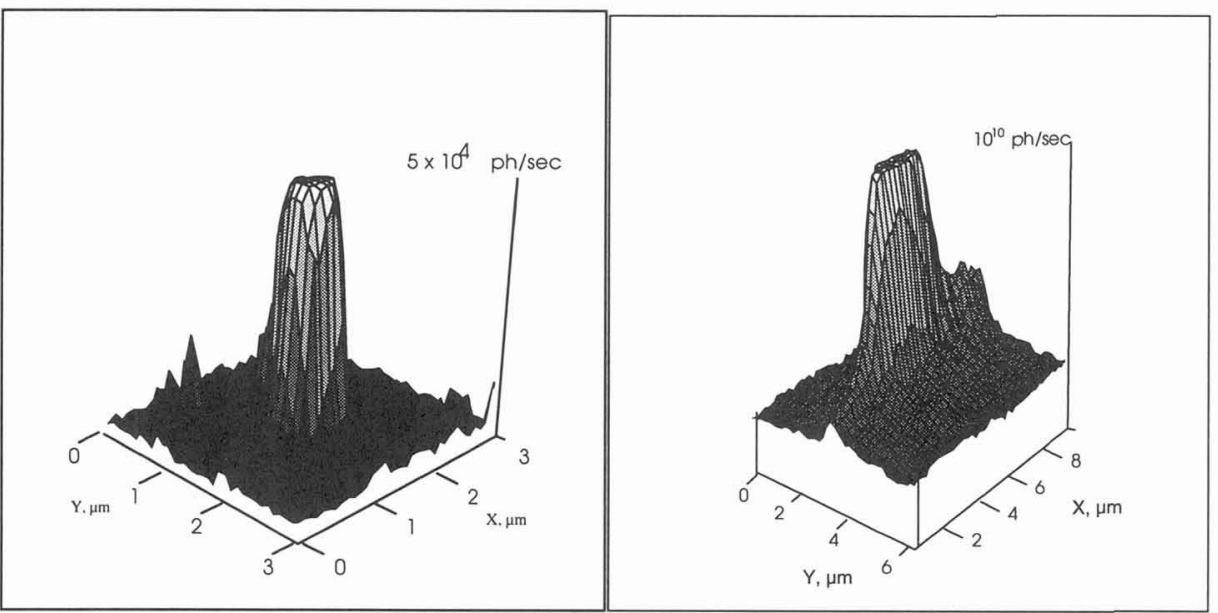

Fig.4 3-D scan of the focal spot obtained by the elliptical Bragg-Fresnel lens using white collimated beam with $50 \mu \mathrm{m}$ input pinhole at $\mathrm{DCI}(\mathrm{a})$ and uncollimated undulator beam at ESRF (b).

\section{APPLICATIONS: X-RAY MICROPROBE}

Designing an X-Ray microprobe on the basis of BFML seems one of the most promising applications of such a lens. The preliminary design of a fluorescence X-Ray scanning microprobe with submicron resolution was tested at the LURE (France) facility in 1992-93 $[13,14]$. An elliptical multilayer Bragg-Fresnel lens has been used for focusing of the white $X-$ ray synchrotron beam at beam energies of $12.4 \mathrm{KeV}$ and $8 \mathrm{KeV}$.
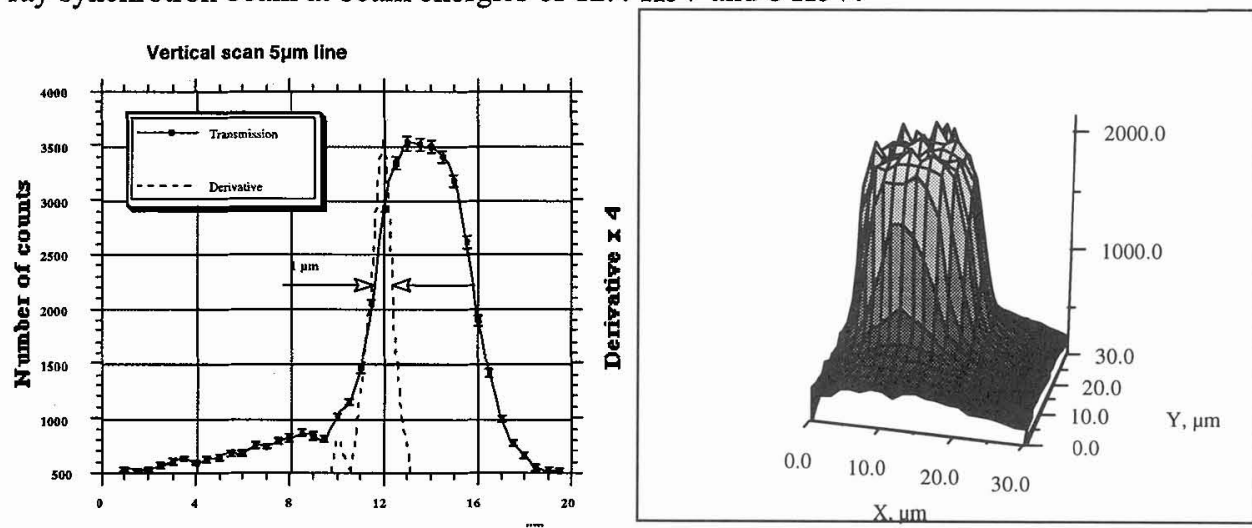

Fig.5. One-dimensional scan image of the gold mask with $5 \mu$ m lines(a) and three-dimensional scan of the $20 \mu$ m pinhole. Transmission mode.

The resolution of the $\mathrm{X}$-ray microprobe was first tested in transmission mode. The test object (gold mask) was placed in the focal plane of the optical system and scanned in both vertical and horizontal directions. The total flux in the focal spot has been measured to be $7 \times 10^{5}$ photons $/ \mathrm{sec}$ for the $100 \mu \mathrm{m}$ input pinhole. Fig.5a shows the variation of the absorbed Xray flux versus position when scanned vertically across $5 \mu \mathrm{m}$ wide gold stripe. Derivation of the transmitted flux in the same figure is shown. Due to the Gaussian photon distribution on to the focal spot a resolution of $0.84 \mu \mathrm{m}$ was obtained with reasonable contrast. A two- 
dimensional scanned image of an $20 \mu \mathrm{m}$ pinhole was also done (see fig.5b). This plot indicates a good signal-to-noise ratio between focused and scattered $\mathrm{X}$-ray beams.

In the fluorescence mode a fluorescence signal was detected by a $\mathrm{Si}(\mathrm{Li})$ detector linked to a computer working as a multichannel analyzer. The fluorescence photon counting rate for the $\mathrm{Ni}$ spectral line was between 10 and 100 counts per second with $3 \mu \mathrm{m}$ spatial resolution. In another 2D study a micro meteorite sample collected from Antarctic by Morette (CSNSM, Orsay, France) was mapped. The result is shown in fig.6. It was achieved in 6 hours: $30 \times 30$ $\mu \mathrm{m}$ area by steps of $3 \mu \mathrm{m}, 180$ seconds per step.

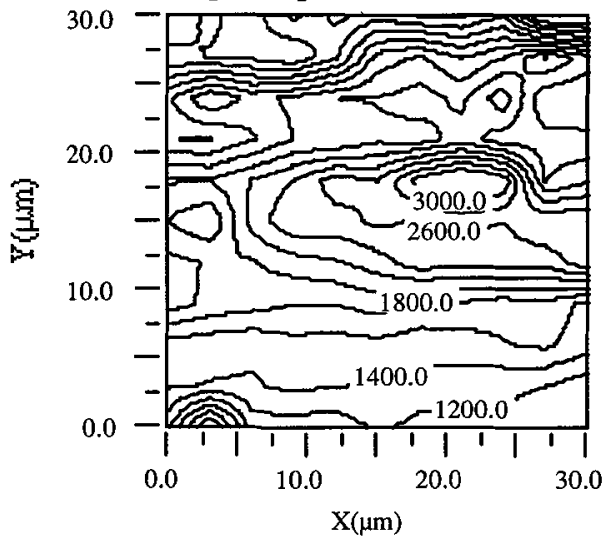

Fig.6 $2 \mathrm{D}$ scan of a micro meteorite $(\mathrm{Fe}(\mathrm{K})$ lines excited with $12.5 \mathrm{KeV}$ photons.

The high sensitivity of the fluorescence microprobe analysis was demonstrated in the experiment made on an undulator at the ESRF facility in 1994 [12]. For that purpose tests were performed with a specially prepared object: a $\mathrm{Cr}$ photomask of $80 \mathrm{~nm}$ thickness deposited on a glass substrate. With this sample the count rate of $\mathrm{CrK}_{\alpha+\beta}$ was of the order of 700 per second for an electron beam intensity of $100 \mathrm{~mA}$. Considering the detector efficiency and absorption this means that up to $2 \times 10^{9}$ photons were concentrated in the focal spot. Moreover, it was measured, that it is possible to increase the flux by 5 times by changing the gap to the maximum of the undulator harmonic.

\section{CONCLUSIONS}

A number of different types of BFML have been tested on the DCI synchrotron source as well as ESRF performing a 2D focusing. At the DCI synchrotron source the beam has been collimated so as to check the spatial resolution limit. Imaging of specially prepared test objects has been achieved at between 8 and $12.4 \mathrm{KeV}$ on photographic plates, transmission and fluorescence tests have been successfully performed. These measurements confirm that the theoretical spatial resolution can be obtained with the present multilayer and BFML technologies. In addition, the efficiency measurements indicate the phase nature of the prepared gratings.

\section{ACKNOWLEDGMENTS.}

The author is very grateful to Prof. Aristov and Dr. M.Brunel for their useful discussions of the results.

This work is supported by the PICS and ULTIMATECH programs of the CNRS (France), the Ministry of Sciences of the Russian Federation and a NATO Linkage Grant N $^{\circ} 921337$. 


\section{REFERENCES}

1. Yu. N. Denisiuk, Sov. Journal of Optics and Spectroscopy, 15, 522- 530, (1963)

2. V.V. Aristov in "X-Ray Microscopy II, ed by D.Sayre, M.Howells, J.Kirz, and H.Rarback, Springer Series in Optical Sciences, Springer-Verlag, 108-117 (1988).

3. V. V. Aristov, Yu. A. Basov, A. A. Snigirev, Journ. Tech. Phys. Letters, 13(2), 114-118, (1987)

4. V. V. Aristov, S. V. Gaponov, V. M. Genkin, Yu. A. Gorbatov, A. I. Erko, V. V. Martynov, L.A. Matveeva, N. N. Salaschenko, JETP Letters, 44(4), 265-267 (1986)

5. V.V. Aristov, A.I. Erko, V.V. Martynov, Rev. Phys. Appl. 23(5), 1623-1630, (1988)

6. T.W. Barbee, Jr., Rev. Sci. Instrum. 60(7) 1588-1595, (1989)

7. A. Erko, B.Vidal, P.Vincent, Yu. Agafonov, V.V. Martynov, D.V.Roshchupkin, M.Bunel, Nuclear Instruments and Methods in Physics Research, A333, 559-606 (1993)

8. A.I. Erko, Journal of X-Ray Science and Technology, V.2(4), 297-316 (1990)

9. V.V. Aristov, A.I.Erko, B.N.Gaifullin, A.A.Svintsov, S.I.Zaitsev, R.R.Jede, H.F.Raith, Microelectronic Engeneering 17, 413-416, (1992)

10. J.Kirz Journ. Opt. Soc. Am. Vol. 64, 301, (1974)

11. A. Erko, Yu. Agafonov, L.A. Panchenko, A. Yuakshin, P. Chevallier, P. Dhez, F. Legrand, Optics Comuns, 106, 1994, p.146-150

12. P.Chevallier P.Dhez, F.Legrand, A.Erko, A.Snigirev, I.Snigireva, A.Suvorov, A.Freund, M.Idir, G.Soullié, A.Mirone, G.Gruibel, Nuclear Instruments and Methods in Physics Research, (A) to be published in 1994

13. Erko A., Chevallier P., Dhez P., Legrand F., Vidal B, Inst. Phys. Conf. Ser. 130 "Proc. of the XIII International Conference on X-Ray Optics and Microanalysis" IOP Publishing, 1992, p. 617

14. F. Legrand, A. Erko, P. Dhez, P. Chevallier, C. Legrand in Proc. of the 4-th International Conference on X-Ray Microscopy, Chernogolovka, Russie, 1993 (to be published) 